\section{Laying down the laws}

\section{When Physics Became King by Iwan Rhys Morus \\ University of Chicago Press: 2005. 288 pp. $\$ 60, £ 42$ (hbk); \$25, £17.50 (pbk)}

\section{Stephen G. Brush}

When did physics become king? And what is its kingdom?

According to Iwan Rhys Morus, a lecturer in history at the University of Wales, it was during the nineteenth century that physics became the most powerful and prestigious science in the United Kingdom and Germany.

That does not necessarily mean that other sciences bowed down to physics - the only other sciences he mentions are chemistry and astronomy, both of which had been dominant in the early part of the century. Apparently, chemistry failed to keep up with physics, while astronomy became more and more dependent on physical instruments and theories.

This is a story about the ascendance of physics as viewed by the public and, more importantly, by government and industry. As Morus puts it, physics became "the ultimate authority in nature". It is a fascinating story, well told and mostly based on the latest research by professional historians of science. But the approach is "unashamedly cultural", or rather, social: high culture appears only in a chapter on romantic nature philosophy.

Morus stresses the role of institutions such as universities, journals and public exhibitions, alongside events that depended on the actions of individuals. Readers who don't have some background knowledge of physics and its history may get the impression that objective scientific factors did not have much influence on the success of physics, although that is not the author's position. While acknowledging the importance of mathematics in the development of theoretical physics, he provides few ical concepts or techniques; this may please some readers but it fails to convey an understanding of what theoretical physicists such as Hermann von Helmholtz, James Clerk Maxwell and Augustin-Jean Fresnel were actually doing.

Why did physics rather than chemistry become the leading science by 1900 ? The credited with establishing the law of energy conservation, the most important discovery in nineteenth-century physical science. This law governed all the physical and biological sciences, and was even believed to explain why women should not do scientific research. Some nineteenth-century scientists argued that "only so much energy could be contained in a woman's body. Its proper purpose was to be directed towards childbirth and nurturing."

Second, Morus believes that the mathematical aspects of physics "made laboratory work respectable for the sons of gentlemen", thereby overcoming class prejudice against the manual labour needed to do experimental science. Third, "its connexions with the world of telegraph cables, electric power, and factory engines made it a practical occupation for the sons of trade".

The final reason that Morus gives for the rise of physics is that it gained favourable equations and no discussion of any mathematauthor's answer is fourfold. First, physics was

\section{EXHIBITION \\ Snow business}

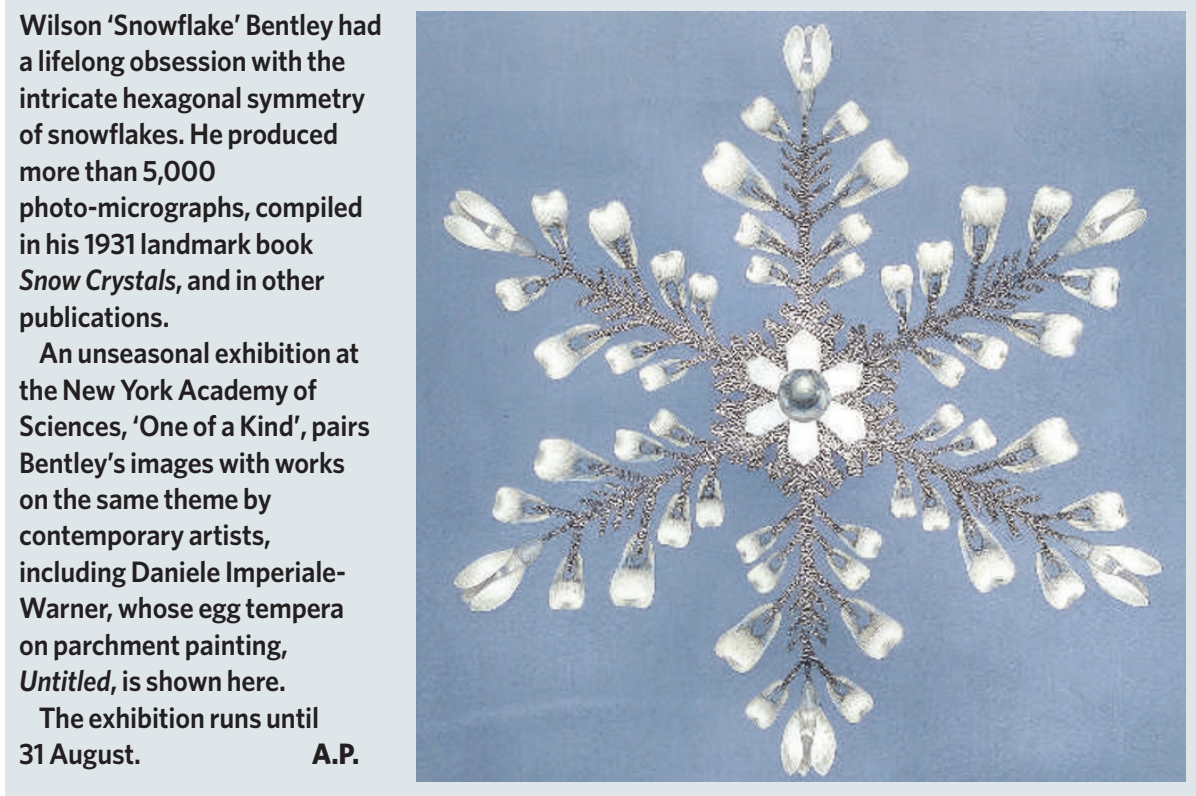

notice from public demonstrations and exhibits, especially of electrical phenomena, and from applications that benefited industry, government and citizens. For those scientists and others fascinated by "mysterious fluids and forces" at the end of the nineteenth century, he says, the electromagnetic-wave experiments of Heinrich Hertz not only confirmed the remarkable prediction from Maxwell's equations of their existence and properties, but also "demonstrated graphically the physicists' power to manipulate nature, to make things happen as if by magic".

Going back up the causal chain, we learn that the University of Cambridge began to stress advanced mathematics because, at the beginning of the nineteenth century, that was the only subject to be tested by written examinations leading to public honours. Attaining such honours was the best way to enter a career in government service in the expanding British Empire. Success in the mathematical tripos examination was supposed to demonstrate the moral and mental characteristics needed for such service. Preparation for this very competitive examination provided excellent training for research in theoretical physics.

Then, around 1870, despite strong university opposition, a laboratory for experimental work was established. This was only possible because William Cavendish, Duke of Devonshire, who had himself attained high honours in mathematics, was chancellor of the university and paid for the laboratory himself. The Cavendish Laboratory got off to an excellent start with the efforts of Maxwell, its first director, and so the University of Cambridge became a world leader in both theoretical and experimental physics. A similar story, combining social and personal factors, can be told about the rise of physics in Germany.

It is impossible to cover all the important aspects of nineteenth-century physics in a text of fewer than 300 pages. However, a serious omission from Why Physics Became King is the establishment of the existence and quantitative properties of atoms. The contributions of Avogadro, Loschmidt, Perrin and others are ignored. Although in the nineteenth century the atom may have been more important to chemistry than to physics, it was thanks to physical theories (especially the kinetic theory of gases) that the speeds, masses and sizes of atoms could be determined. This transformed a philosophical speculation into a legitimate scientific concept and expanded the kingdom of physics into fertile new territory. Stephen G. Brush is professor of the history of science in the Department of History and Institute for Physical Science and Technology, University of Maryland, College Park, Maryland 20742, USA. 